\title{
13 Experiences from the Kenya \\ National Commission on \\ Human Rights (KNCHR) \\ on the promotion and \\ protection of sexual and \\ reproductive health and rights
}

\author{
Shatikha S. Chivusia
}

\section{Introduction}

The Kenya National Commission on Human Rights (KNCHR) is a National Human Rights Institution (NHRI) established under both the Constitution and Statute laws of Kenya. The Commission's core mandate of protecting and promoting human rights was further enhanced under the Prevention of Torture Act (2017) to investigate complaints of torture, cruel and inhuman and degrading treatment or punishment within the country.

KNCHR enjoys 'A' status accreditation under the United Nations Paris Principles which were adopted by the General Assembly in 1993. They provide for the mandate of NHRIs to protect human rights through inter alia, receiving, investigating and resolving complaints; mediating conflicts and monitoring activities. Further, NHRIs are obliged to promote human rights observance through public education, outreach, media engagement, publications, training and capacity building as well as advising and assisting the government in respect thereto. Based upon these guidelines, the mandate of KNCHR is stipulated under its constitutive Act and implementation of the same has led to its above referred to accreditation as per the six criteria of the Paris Principles (broad mandate based on international human rights norms ad standards, autonomy from government, guaranteed under constitutive law, pluralism, adequate resources and adequate powers of investigation). More information about KNCHR may be found on its official website.

\section{Understanding Sexual and Reproductive Health and Rights}

Sexual and Reproductive Health and Rights (SRHRs) are said to encompass all of those rights regarding ones' sexual and reproductive health and by extension, life itself. Sexual and reproductive health rights cannot be actualized in

DOI: $10.4324 / 9781003175049-13$ 
isolation as they are closely linked to other human rights such as the right to bodily integrity, the right to human dignity, the right to health/ highest attainable standard of health, the right to life, the right to privacy and freedom from violence and all forms of discrimination, amongst others.

According to information available on the website of Choice for Youth and Sexuality. ${ }^{1}$

'The term SRHR combines four separate but interrelated concepts: Sexual Health $(\mathrm{SH})$, Reproductive Health $(\mathrm{RH})$, Sexual Rights (SR), and Reproductive Rights $(R R)$. Sexual and Reproductive health and rights cover the right to decide if, when and how often to have children, the right to live free from disease, the right to have access to accurate, comprehensive and confidential information etc; while Sexual Rights cover the right to sexual pleasure, the right to sexual expression, the right to sexual privacy, the right to have access to the full range of contraceptives and the right to choose your partner amongst others'.

The World Health Organization (WHO) has defined sexual health as 'a state of physical, emotional, mental and social well-being in relation to sexuality'2 while the International Conference on Population and Development (ICPD) Programme of Action described reproductive health as concerning peoples' ability to reproduce and the freedom to make informed, free and responsible decisions about their reproductive behaviour based on access to a range of reproductive health data, goods, facilities and services.

It is noteworthy that although internationally recognized, SRHR are still considered controversial and also contentious. This is especially so when issues of sexual and gender diversity that have not been fully embraced in many communities are mixed into the discussion. SRHR rest on the recognition of the basic rights of all couples and individuals to decide freely and responsibly the number, spacing and timing of their children. In addition, parties should have the information and means to do so, plus the right to attain the highest standard of sexual and reproductive health. SRHR also encompass the right to make decisions concerning reproduction free of discrimination, coercion and violence, as expressed in several human rights documents. ${ }^{3}$ It should also be noted that just as the right to the highest attainable standard of health does not only mean absence of disease and infirmity but also includes the right to the provision of preventive, curative and palliative health care, including underlying determinants of health, ${ }^{4}$ the same is applicable to the right to sexual and reproductive health. It extends beyond sexual and reproductive health care to the underlying determinants such as access to safe and potable water, adequate sanitation, adequate food and nutrition, adequate housing, safe and healthy working conditions and environment, health-related education and information, and effective protection from all forms of violence, torture and discrimination amongst other human rights violations that have a negative impact on the actualization of the right to sexual and reproductive health.

The Committee on Economic, Social and Cultural Rights ${ }^{5}$ has rightly observed that numerous legal, procedural, practical and social barriers seriously restrict people's access to the full range of sexual and reproductive health 
facilities, services, goods and information and that full enjoyment of this right remains a distant goal for many in the world, especially women and girls. The Committee singled out lesbian, gay, bisexual, transgender and intersex persons and persons with disabilities as individuals and groups that experience multiple and intersecting forms of discrimination. These groups' situation is further exacerbated by their exclusion in both law and practice which places further restrictions on their full enjoyment of the right to sexual and reproductive health.

\section{Kenya's Normative Framework on Sexual and Reproductive Health Rights}

Sexual and Reproductive Health and Rights are fundamental human rights that are guaranteed in various international and regional human rights instruments as well as national laws and policies ${ }^{6}$ in Kenya. As a matter of fact, the supreme law of the country provides for the application of international treaties and conventions that Kenya has ratified alongside domestic law. Though there is currently no human rights instrument under international law that provides specifically for sexual and reproductive health and rights, there exists a plethora of provisions housed in various international and regional instruments which are geared towards the advancement of these rights. As was rightfully noted during the International Conference on Population and Development (ICPD) Programme of Action);-

...sexual and reproductive health rights are not a new set of rights; rather they are rights already recognised in human rights instruments. ${ }^{7}$

Amongst the instruments with specific protections on sexual and reproductive health rights are the Covenant on Economic, Social and Cultural Rights (1966); Covenant on Civil and Political Rights (1966); Convention on the Elimination of all forms of Racial Discrimination (1966); Convention on the Elimination of all forms of Discrimination against Women (1979), Convention Against Torture and Other Cruel, Inhuman or Degrading Treatment or Punishment (1984); Convention on the Rights of the Child (1989) and Convention on the Rights of Persons with Disabilities (2006). At the African regional level, the chief instrument that provides for sexual and reproductive health and rights is the African Charter on Human and Peoples' Rights (1981)[ The African Charter] which states that every individual shall have the right to enjoy the best attainable state of physical and mental health. Similar provisions are contained in the African Charter on the Rights and Welfare of the Child (1990) and the Protocol to the African Charter on Human and Peoples' Rights on the Rights of Women in Africa popularly known as the 'Maputo Protocol' (2003).

The international Convention on the Elimination of all forms of Discrimination against Women (CEDAW) promotes the right to health, including family planning. The CEDAW Committee in its general recommendation 
24 has also clearly indicated that women's right to health includes their sexual and reproductive health thus implying that States have obligations to respect, protect and fulfill rights related to women's sexual and reproductive health. The Special Rapporteur on the right of everyone to the enjoyment of the highest attainable standard of physical and mental health maintains that women are entitled to reproductive health care services, goods and facilities. The same ought to be availed in adequate numbers, be physically and economically accessible, without discrimination, and be of good quality.

The CESCR General Comment 14 explains that the provision of maternal health services is comparable to a core obligation which cannot be derogated from under any circumstances, and that States have the immediate obligation to take deliberate, concrete, and targeted steps towards fulfilling the right to health in the context of pregnancy and childbirth. The Committee considers the right to health in all its forms and at all levels to contain the following in every particular State party;-availability of functioning public health and healthcare facilities, goods and services, as well as programmes in sufficient quantity; accessibility physically, economically and to information in non-discriminatory terms; acceptable and of quality which entails, inter alia, skilled medical personnel; scientifically approved and unexpired drugs and hospital equipment; safe and potable water plus adequate sanitation. In its General Comment 22, the Committee has affirmed that the enjoyment of the right to health includes SRHR. The Committee further affirms that states must ensure the realization of the SRHR of women and girls on a non-discriminatory basis.

The Children's Convention also provides strong protection on their right to access sexual and reproductive health services together with the rights to equality and non-discrimination. This includes protection of girls' rights as a result of the stigma surrounding sexuality in most societies and the attendant discrimination and inequalities that they face daily in life. The Committee on the Rights of the Child (CRC) in its general comment 4 has also advocated for the realization of children's right to sexual and reproductive health services and obliged states to ensure universal access to sexual and reproductive health interventions. Such realization would include adolescent access to short and long-term contraceptive methods, emergency contraception, safe abortion and post-abortion care services irrespective of whether abortion itself is legal in the state parties' jurisdiction. The CRC has on several occasions strongly condemned and called for the eradication of socio-cultural practices that jeopardize children's reproductive rights such as child marriage and female genital mutilation.

The adjudication of several cases on children's rights to sexual and reproductive health services by various International and regional human rights bodies is an indication of the strong advocacy for this right for children. For example, the United Nations Human Rights Council Committee held in KL $v$ Peru (UNHRC 2005) that denying abortion services to a child who was carrying a pregnancy that posed a risk to her life and mental wellbeing amounted to a violation of her right to privacy, and also to cruel, inhuman and degrading treatment, inter alia. The European Court of Human Rights (ECtHR) also 
made similar findings in $R$ and $S v$ Poland (ECHR 2008) where a child had intentionally been obstructed from accessing abortion services.

At the continental level, there exists a normative and institutional framework in Africa for the promotion, protection and realization of SRHR, which continues to evolve and become stronger. Amongst these are the Maputo Protocol already cited above, the Solemn Declaration on Gender Equality in Africa, the Continental Policy Framework on SRHR, and the Maputo Action Plan. Further to the above are the African Charter on the Rights and Welfare of the Child, the African Youth Charter and the AU Gender Strategy.

The Africa Charter which is the foundation of the African human rights system and the parent treaty of the Maputo Protocol enshrines the principle of non-discrimination on all grounds including on the basis of sex. It also obliges states to eliminate discrimination against women and girls and to protect their rights. It was the key determinant in the creation of the Special Rapporteur on the Rights of Women in Africa mandate and guarantees women's right to health, including sexual and reproductive health. The adoption of the Maputo Protocol by the African Union in 2003 ushered in a new era in the advancement of women's human rights, including SRHR in Africa. ${ }^{8}$ The Maputo Protocol also calls upon States Parties to take all appropriate measures to 'protect the reproductive rights of women by authorizing medical abortion in cases of sexual assault, rape, incest, and where the continued pregnancy endangers the mental and physical health of the mother or the life of the mother or the foetus. This provision has been hailed as affirming a substantive equality approach to addressing the sexual and reproductive health and rights of women in the region. ${ }^{9}$

Women's rights to sexual and reproductive health enumerated therein include the rights to control their fertility, the number and spacing of children, choice of contraception method, and access to family planning education. It is noteworthy that this is the first 'international human rights instrument to recognize abortion as a women's right that should be enjoyed without restriction or fear of being prosecuted under certain conditions. Many African countries are however, yet to undertake the necessary legislative reforms needed towards domesticating the relevant provisions of the Maputo Protocol especially in the area of women's sexual and reproductive rights. The practical reality is therefore that many women and girls continue to have limited access to family planning and accessing safe and available abortion services even in cases where it is legal.

Three General Comments have been adopted with regard to the Maputo Protocol two of which are by the African Commission on Human and Peoples' Rights and explain their normative content. The comments also articulate measures which states should undertake to fulfil their obligations under the Protocol. The first general comment on Article 14 (1) (d) and (e) with regard to women's rights and HIV, and the second general comment concerns the rights to reproductive freedom, family planning and safe abortion. The latter may also be utilized to guide drafting and presentation of State periodic reports particularly when reporting on legislative and other measures taken to promote and protect the sexual and 
reproductive health of women and girls. The Third General Comment, adopted in 2017, jointly by the ACHPR and the African Committee of Experts on the Rights and Welfare of the Child focuses on ending child marriages and refers to both the Maputo Protocol and the African Children's Charter.

The revised Continental Policy Framework on SRHRs translated into the Maputo Plan of Action provides guidance to African states on how to implement the ICPD Programme of Action (UN 1994) and the Abuja Declaration (AU 2001). Of the Fifty-two countries that have signed the Maputo Protocol, only forty have ratified it and seven of these with reservations, which mostly touch on women and girls' SRHR particularly with regard to marriage and access to safe abortion. The import of this is that many factors still impede women's enjoyment of the provisions of the Maputo Plan of Action. Its implementation is further hampered by factors such as inadequate health legislation and infrastructure, weak political commitment and leadership, inadequate financing and high donor dependency, coupled with poor women empowerment. The situation is further exacerbated by cultural norms and practices in highly patriarchal societies, which continue to entrench and justify violation of women's rights. ${ }^{10}$

Another component of the continental legislative and normative framework is the Solemn Declaration on Gender Equality in Africa which reaffirms African states' commitments to gender equality and parity and the protection of women and girls' rights. Further, the African heads of state endorsed the Continental Policy Framework on Sexual and Reproductive Health Rights (CPF) in January 2006. It offers guidance to policy formulation by member states in the implementation of the ICPD Plan of Action (PoA) and the Millennium Development Goals (MDGs). The CPF identified the following eight core strategic areas which it called for mainstreaming and harmonization into all development initiatives-maternal mortality and morbidity, infant and child mortality, contraceptive use and family planning services, unsafe abortion, sexually transmitted infections and HIV and Aids, Adolescent Reproductive Health, Female Genital Mutilation and Gender-based Violence. The CPF also identified the challenges highlighted above and sought to strengthen implementation of the recommendations of the Abuja Declaration of the 2001 Summit of Heads of State and Government to increase resources for the health sector as a means to realization of SRHR on the continent.

With specific regard to youth and adolescents, the two main regional frameworks are the African Charter on the Rights and Welfare of the Child and the African Youth Charter which both seek to prioritize youth development and empowerment through their participation in debates and decision-making.

Further, Africa's first Gender Equality and Women's Empowerment Strategy reaffirms its commitment to advancing gender equality and is expected to contribute to attaining Agenda 2063 visions for gender equality. During the consultative process on the formulation of the strategy, child marriage, FGM, gender-violence against women, eradication of maternal mortality and HIV and AIDS were given priority. Further, attention was also given to ensuring 
affordable and accessible SRHR especially for the youth in terms of adolescent pregnancies, commercial sexual exploitation, lack of youth-friendly SRHR services and sexual violence/harassment in schools.

\subsection{Kenya's Domestic Legal and Policy Framework}

Kenya's domestic law contains provisions for the right to the highest attainable standard of health, which includes the right to reproductive health care for every person. Provision for emergency medical treatment has also been made in absolute terms and on condition that it should never be denied. The State is further obliged to provide social security as appropriate, to persons who are unable to support themselves and their dependents. To realize this right, the Kenyan government has put in place several statutory provisions and policies amongst which is the Prohibition of Female Genital Mutilation (FGM) Act, 2011. This Act prohibits the practice of FGM, safeguards against violation of a person's mental or physical integrity through the said act and other connected purposes. It defines what constitutes FGM, provides for the forms of crimes and punishments thereunder and also aims to reduce the scale of the practice with the target of eliminating it wholly. Methods of assisting the survivors of FGM in terms of medical assistance and actions that the government is supposed to undertake to eradicate the practice are also given. This law has rendered the practice of FGM a crime against the State and punishable by imprisonment and /or fines. Constitutional guarantees in Kenya for women and children to be free from all forms of discrimination are also available, with the right to dignity and physical integrity safeguarded. Further, freedom from violence; the right to health and the right not to be compelled to undergo any harmful cultural practices have been protected.

Kenya also has the Sexual Offences Act 2006 which came into force in July 2006 and makes provision for sexual offences, their definition, and prevention. It provides protection to all persons from harm, unlawful sexual acts and similar conduct. The law was hailed for bringing clarity on the definition and types of sexual offences apart from introducing more strict sentencing guidelines based on provision of 'minimum sentences'. It also provides for the management of medical treatment and court processes that protect the dignity of victims. Unfortunately, however, the criminal justice system in Kenya has faced various challenges in addressing the plight of victims and survivors of sexual offences thus putting a dent to the expected achievements of this law. Further, few convictions in relation to the number of reported cases and the perceived high incidence of sexual crimes in the country point to constrain in the prosecution of sexual offences and thus the expected impact of this law.

The 2001 Children's Act of Kenya aimed to domesticate the Convention on the Rights of the Child (CRC) and the African Charter on the Rights and Welfare of the Child. Among its provisions is prohibition of harmful cultural practices such as child marriages, FGM and sexual offences 
There are also several policies in addition to the above laws that have been developed such as the National Adolescent Sexual and Reproductive Health Policy, the Contraceptive Commodities Security Strategy (2007-2012), the Contraceptive Policy and Strategy (2002-2006), Reproductive Health Policy of 2015 and an institutional framework to promote and protect the sexual and reproductive health rights of Kenyans. The Adolescent Reproductive Health and Development Policy, 2003, aims at enhancing SRH status of adolescents in Kenya and contributes towards realization of their full potential in national development. The Policy seeks to bring adolescent sexual and reproductive health and rights issues into the country's mainstream health and development agenda. This is in line with the country's international and regional obligations which include the Ministerial Commitment on Comprehensive Sexuality Education and SRH Services for Adolescents and Young People in Eastern and Southern Africa (ESA, 2013), the Convention on the Rights of the Child and the Program of Action of the International Conference on Population and Development. Added to these and other instruments already listed above is the Millennium Development Goals (MDGs) approved by the World Summit on Sustainable Development in September 2000. The implementation of the Adolescent Reproductive Health and Development Policy is guided by the principles of respect for human rights and fundamental freedoms, responsiveness to the varying sexual and reproductive health needs of adolescents and provision of holistic and integrated ASRH information and services. The policy also recognizes the critical role parents, guardians and communities play in the promotion of SRHRs; involvement of adolescents in the planning, implementation, monitoring and evaluation of ASRH programs plus the utilization of evidence-based interventions and programming.

The National Condom Policy and Strategy (2009-2014) on the other hand seeks to ensure adequate national supply of and access to condoms, coupled with public education and advocacy to increase use among those in need but not utilizing condoms. The policy and strategy was based on the findings of a study by the National AIDS Control Council (NACC) which estimated that about 1.5 million people had died of AIDS as of June 2000 since detection of the pandemic in Kenya in the early 1980s. The pandemic had resulted in more than 1 million children being orphaned, and a suspected significant drop in life expectancy at birth. The objectives of the Policy and Strategy provide that no barriers should exist to access and use condoms by those who need and want to use them. Further, that user charges and revolving funds in public service delivery points should be established bearing in mind equity considerations plus the cost of condoms by providers and users. Another objective is to have in place an effective management of condom supply pipeline.

The National Reproductive Health Policy, 2007 consolidates efforts by the government to enhance the reproductive health status of all Kenyans by increasing equitable access to reproductive health services and by improving the quality, efficiency and effectiveness of services provided at all levels. The policy focuses on service delivery to the wider public and the promotion of healthy 
lifestyles of individuals and communities in tandem with the Millennium development goals (MDGs). Its purpose is to improve maternal health, reduce neonatal and child mortality, reduce the spread of HIV/AIDS and promote women's empowerment and gender equality. The policy was developed as a result of the response to the ICPD in 1994 which called for the development of comprehensive reproductive health policies, programmes and implementation plans. It emphasized the strategic roles of information, education and community mobilization and participation in promoting and protecting SRHR.

On the other hand, the National Reproductive Health Policy is guided by principles of respect for human rights and freedoms and provides for the freedom of couples and individuals to decide responsibly the timing, number and spacing of their children. The right to have access to requisite information and education for making informed decisions is also protected. The Policy further calls for all people to freely and responsibly decide on all aspects of their sexuality, including the right to be free from conditions that interfere with their sexual health. Other aspects are protection from harmful practices, sexually acquired infections, complications associated with menopause and andropause, and coercion into sexual acts and other forms of sexual violence. The policy provides priority actions in Safe Motherhood, Maternal and Neonatal Health, Family Planning and Adolescents/Youth Sexual and Reproductive Health. Gender Issues, Sexual and Reproductive Rights, HIV and AIDS, Reproductive Tract Infections, Infertility, Cancers of Reproductive Organs and Reproductive Health for Elderly Persons are also provided for.

The above discussion indicates that clearly, Kenya is obliged by virtue of her legal regime to enforce the right to the highest attainable standard of health for its citizenry (including SRHR) and to take steps towards progressively realizing the rights recognized in the CESCR. This right has been interpreted variously including non-confinement to not only the right to health care only but expansion to include the right to control one's health and body, the right to access essential health information and freedom from interference with one's health, among others

\subsection{Access to SRHR goods and services in Kenya}

Apart from the legal framework available in Kenya with regard to the realization of sexual and reproductive health rights, it is important to briefly discuss the status of health facilities and healthcare services in the country, which form part of the operating environment for KNCHR's advocacy work.

Provision of health care services in Kenya has on several occasions been crippled and even grounded due to industrial action by its more than 600 doctors demanding for better terms of service, improvements to dilapidated public health facilities and for the government to address the prevailing huge shortage of doctors. The worst of these strikes went on for more than a hundred days and affected over 2500 public health facilities resulting in the death of 
many patients due to lack of medical care. ${ }^{11}$ In January 2018, doctors, under the umbrella body known as the Kenya Medical Practitioners, Pharmacists and Dentists Union once again gave a strike notice and threatened to down their tools by February over alleged failure by universities and medical colleges to pay allowances due to their members. ${ }^{12}$ Fortunately, the industrial action was averted when the doctors' body reached an agreement with the government over their terms of service.

In addition to the doctors' strikes, the provision of health care services is often further negatively impacted through frequent downing of tools by other medical practitioners especially nurses. Recently, one of their strikes went on for over one hundred and fifty days. ${ }^{13}$ Added to the situation are also strikes by university lecturers, which indirectly impacts health care provision due to their role in medical schools and affiliated referral hospitals. In the premises, the Kenyan public is many times left in a precarious position with regards to accessing health care services taking into account already existing numerous impediments that have to be surmounted. ${ }^{14}$ At the core of the many doctors' strikes has always been the contention about devolution of health care services to county governments under the devolved system of government that was ushered in by the 2010 Constitution. Doctors preferred to have a national body responsible for management of their services and a scheme of employment as opposed to this status quo.

\section{The Experiences of KNCHR in Addressing Sexual and Reproductive Health and Rights}

The Paris Principles which came into effect in 1993 and on which the establishment of National Human Rights Institutions (NHRIs) is grounded, bestow on them a national mandate to protect and promote the respect for human rights. This may be undertaken through various activities such as receiving, investigating and resolving complaints of human rights violations; mediating conflicts, monitoring and observing the national human rights landscape, promoting observance of human rights through public education, outreach, the media, publications, training and capacity building as well as advising and assisting governments concerning the promotion and protection of human rights. NHRIs form an integral part of the international human rights mechanisms and have an essential role in promoting the implementation by states of international obligations with regard to actualization of human sexual and reproductive health rights. More importantly, NHRIs can play a crucial role in advancing SRHR at the national level through its promotional and protective activities. ${ }^{15} \mathrm{KNCHR}$, being no exception to other NHRIs, has likewise been endowed with a broad national mandate ${ }^{16}$ which it has exercised in various ways. The following activities are illustrative of KNCHR's work with specific regard to the realization of reproductive and sexual health rights. 


\subsection{A Public Inquiry into Violations of Sexual and Reproductive Health Rights}

The 2008-09 Kenya Demographic and Health Survey (KDHS $)^{17}$ findings were quite disturbing. They contained indications that most Kenyan women's first sexual intercourse was forced and against their will especially for women aged between 15 and 49 years (12\%). The study further revealed that one in five Kenyan women $(21 \%)$ has experienced some form of sexual violence. In addition to the above, evidence from the Kenya Police Crime Report and Data for 2007 indicated 876 rape cases, 1,984 cases of defilement, 181 cases of incest, 198 cases of sodomy, 191 cases of indecent assault and 173 cases of abduction. In 2008, The Kenyan Police force listed 'Offences against morality' as making up $5 \%$ of the total reported crimes across the country. It was against this backdrop that in 2009, the Federation of Women Lawyers (FIDA) - Kenya and the Centre for Reproductive Rights of the United States of America (CRR), ${ }^{18}$ filed a complaint with KNCHR regarding systematic violation of women's reproductive health rights in many public health facilities. FIDA and CRR's chief complaint was based on the findings of a joint study they had conducted between November 2006 and May 2007 regarding Pumwani Maternity Hospital, which is Kenya's largest maternal health care facility. The complaint prompted the Commission to launch an expanded Inquiry into the extent of violation of sexual and reproductive health and rights within the country in line with its mandate as an NHRI, to investigate or research matters in respect of human rights violations and make recommendations to improve the functioning of State organs. The objective of the Inquiry was to establish the extent and nature of violation of sexual and reproductive health and rights in the country and provide appropriate recommendations and redress measures.

The nationwide public inquiry was conducted in 2011 and proved to be a benchmark on the extent of the enjoyment of sexual and reproductive health and rights as per Kenya's 2010 Constitution. Other objectives of the inquiry were to:

- establish the adequacy and efficacy or otherwise of the legal and policy framework governing the implementation of sexual and reproductive health rights in Kenya;

- assess the extent to which the government and non-state actors comply with their obligations relating to sexual and reproductive health rights,

- determine the extent of awareness and pursuit of sexual and reproductive health rights in Kenya and

- identify and document cases of violation of sexual and reproductive health rights in Kenya.

In summary, the inquiry revealed that SRHR in Kenya are violated on several grounds amongst which are unavailability of essential sexual and reproductive health services, difficulties in accessing the services owing to distance and/or 
cost, high charges levied on the services- making them beyond the reach of majority indigent persons, poor quality of the available services and the lack of sensitivity to the cultural norms and beliefs of the people in service delivery. Further, the State was found to have failed to comply with its international and regional obligation to dedicate the requisite minimum of its available resources to progressively realize the right to sexual and reproductive health, especially under the Abuja Declaration already mentioned above.

With regard to sexual violence, a WHO Report has documented that various forms of sexual violence take place in Kenya under differing contexts. ${ }^{19}$ The contexts include rape by strangers, within marriage and dating relationships plus systemic rape during armed conflict. Unwanted sexual advances also known as sexual harassment at the work place (such demand for sex in return for favours, services or promotion at work), defilement and sexual abuse of persons with disabilities, forced marriage or cohabitation including child marriages, denial of the right to use contraception or the choice to use other measures to prevent unwanted pregnancy and sexually transmitted diseases, forced abortion, forced prostitution and trafficking of persons for purposes of sexual exploitation, and violent acts against the sexual integrity of mainly women through such acts as female genital mutilation and forced virginity inspections being some of the other contexts. The KNCHR inquiry received a lot of witness submissions on the issue of sexual violence. Of particular note were presentations from areas that had experienced heightened conflicts where it was used as a weapon of subjugation. Reports of incidences of marital rape were also received. ${ }^{20}$

Another finding of the Inquiry was that effects of sexual violence were profound on the victim's reproductive health. This was apart from the resultant unwanted pregnancies and eventual unsafe abortions. Other effects noted were sexually transmitted infections including HIV and AIDS, gynaecological complications, stigma, psychological trauma and in extreme cases disability or even death. Evidence also indicated rejection and abandonment by partners especially for female victims. Factors that perpetuate sexual violence were found to be numerous and amongst those recorded as disproportionately affecting women compared to men included:-

'the unequal power relations where laws, policies, community practices and beliefs 'conspire' to deprive women autonomy in private and public spheres' ${ }^{21}$

An earlier report ${ }^{22}$ that had also made similar findings listed low levels of awareness of the law among the public, socioeconomic barriers amongst women, inability to negotiate safe sex and harmful cultural practices or traditional beliefs together with the culture of impunity that has normalized sexual abuse of females in most societies as key causes of sexual violence. The complexity of the Kenyan justice system from the perspective of the common person, who also finds it intimidating, was also singled out as a perpetuating factor. ${ }^{23}$ Among the identified barriers to access remedies by survivors of sexual violence were lack of knowledge about the existence of the services, inaccessibility in terms 
of distance and cost, absence of integrated services, difficulty in accessing documentation to prove sexual violation, in particular the notorious P3 Form ${ }^{24}$ plus the burdensome and often humiliating justice system which has already been mentioned above.

The KNCHR Inquiry further found that incidents of sexual violence continue despite the various national, regional and international frameworks already in place and aimed at addressing this phenomenon. On this basis, KNCHR made several recommendations to the Kenyan government which would strengthen how to minimize sexual violence and to safeguard reproductive health rights. Key recommendations were for Kenya to;-

- Urgently ratify the Optional Protocol to CEDAW to enable citizens file individual complaints to the Monitoring Committee under its procedures.

- Provide survivors of sexual violence with medico-legal and psychosocial support

- The Ministry of Health to work with stakeholders to disseminate and popularize the Guidelines on Management of Sexual Offences

- Expand the range of health facilities to have capacity to serve survivors of sexual and gender-based violence countrywide

- Remove barriers that hinder access to justice in respect of cases of sexual violence with a review of the prosecution requirements that are of a technical nature

On its part, KNCHR undertook to create awareness on sexual violence, educate the public on procedures to be followed when violation occurs and to continuously monitor and document cases of sexual violence with the aim of holding the duty bearers accountable. The findings from the inquiry were published into a report ${ }^{25}$ that continues to be used for advocacy purposes and to inform policy and legislative interventions by various government agencies.

The report also made a number of fundamental recommendations for consideration by other stakeholders. ${ }^{26}$ As a follow-up to these recommendations, KNCHR carried out an audit exercise in 2017 to measure the extent to which the state has implemented the same. Of particular concern was progression made towards realizing the highest standard of health as provided for in the Constitution. While the audit exercise is still on-going and has yet to be finalized, preliminary findings indicate a noticeable improvement in several areas. Among these is the provision of free maternal health care in public facilities that has led to an increased number of women delivering in hospitals and thus enhancing safe delivery by pregnant mothers. In addition, a policy on free maternal health care has been formulated and there is an increase in the uptake of family planning facilities and services. Several structural measures have also been put in place to enhance accessibility of family planning facilities and services. These facts not withstanding however, much still needs to be done to enhance the realization of sexual and reproductive rights in Kenya. Still in existence are barriers towards access to justice by survivors of sexual 
violence, especially those stemming from political violence and unrest, from defilement cases, and notable delays in the prosecution and finalization of sexual and gender-based violence (SGBV) cases. Added to this is the heavy financial weight that survivors of SGBV bear as currently there exists no public structure to support them financially or even provide them with a safe haven in instances where violations occur domestic relations. Added to the above, sexual minorities continue to face discrimination and stigma in accessing health services while the vulnerable and marginalized groups encompassing adolescents/youth, people with disabilities, people living with HIV and AIDS and refugees have not been prioritized. This gap can be addressed through provision of appropriate services and centres at county level. Preparation of the final audit report is still under way and the findings therefrom will provide another key advocacy tool in Kenya's journey towards the protection, promotion and fulfilment of Sexual and reproductive health rights.

Further to the aforesaid, the commission, in partnership with the Africa Alliance for Women's Reproductive Health and Rights (IPAS) ${ }^{27}$ Kenya has embarked on advocacy efforts to move the Kenyan state to lift its reservations under Article 14 (2) (C) of the Maputo Protocol. ${ }^{28}$ The advocacy exercise targets members of parliament as critical actors due to their legislative mandate and especially with regard to voting on Kenya's ratification of international treaties and conventions. A component of the exercise will include training and awareness-raising amongst parliamentarians on the effects that this reservation places on Kenyan women and girls especially during conflict times. Joined with this are efforts by KNCHR to lobby the Ministry of Health to enact Guidelines on Abortion as provided for under the Constitution which once adopted shall go a long way in procuring emergency abortion when required.

The above exercises by KNCHR provide an example of how NHRIs can effectively address realization of SRRH in their countries. While the full implementation of KNCHR's recommendations by the state and other actors has proved limited so far, the documentation of evidence-based violations of SRHR in Kenya in 2012 provides a benchmark against which future similar exercises may be measured. Further, the Inquiry report provides a baseline for the government and other actors to monitor and measure improvement of requisite services and goods to the public in actualization of the various relevant rights. It will prove valuable in addressing gaps and trends towards realizing sexual and reproductive health rights in Kenya.

\section{Monitoring, Documentation and Redress of Electoral Related Sexual and Gender Based Violence (SGBV) Cases During and after the 2017 Elections}

Kenya's history of electoral violence can be traced back to its independence elections and continues to incorporate sexual violence as a weapon. The aim of electoral-related sexual violence is mainly to limit and or punish expression of choice or even intimidate and punish those perceived to have alternative 
political views. It should be noted that sexual violence strikes at the core of human dignity and is often accompanied by violation of several other human rights such as the rights to life; dignity; liberty and security of the person. Further, sexual violence infringes on the rights to freedom from torture, cruel, inhuman and degrading treatment; freedom from discrimination; and the right to highest attainable standard of health. The physical and mental consequences attendant to sexual violence have been found to be extremely dire to the survivors, their families and even society at large.

During Kenya's 2007/8 Post election violence, KNCHR, together with other stakeholders including the Commission of Inquiry into Post Election Violence popularly known as the Waki Commission ${ }^{29}$ and later the Truth Justice and Reconciliation Commission (TJRC) documented over 900 cases on sexual violence. KNCHR's documentation efforts resulted in its nowfamous report titled 'On the Brink of the Precipice ${ }^{30}$ which found that women and children had been particularly targeted for rape on the basis of their ethnicity and thus perceived political affiliation. Opportunistic rape also occurred in the internally displaced persons' [IDP] camps with perpetrators being both security agents and civilians. Though efforts for accountability by KNCHR and other actors suffered a setback when the Office of the Director for Public Prosecutions held that none of the files brought before his office contained sufficient evidence to warrant prosecutions, KNCHR continues to date to press for justice for the survivors of the 2007/08 post-election violence in various ways. First was through filing two cases in court to seek compensation for the 2007/8 sexual violence survivors which are still ongoing, and also through being part of the Transitional Justice Network (TJN) that comprises civil society actors and government agencies working together with the office of the Attorney General to set up a framework for reparations to survivors of sexual violence.

In furtherance of its tradition to monitor and document human rights issues during the electoral period, KNCHR once again worked in partnership with a number of civil society organizations and individuals to document cases of sexual and gender-based violence between April 2017 and April 2018 which surrounded Kenya's 2017 General Elections. The 2017 electoral environment culminated in civil unrest by way of political protests and use of violent force by law enforcement agents. In total, two hundred and one (201) cases were recorded in the commission's publication known as 'Silhouettes of Brutality' with the conclusive finding that the chief perpetrators were both civilian and the security agents. According to records within the Commission's purview, security agents were responsible for $54.55 \%$ and civilian for $45.45 \%$ of sexual violence linked to the 2017 electoral cycle.

The type and forms of sexual violence included gang rape and rape at over $71 \%$ with the least percentage being of attempted defilement at $1.07 \%$. Sodomy contributed to $1.60 \%$ of the reported cases, $9 \%$ of the cases affected minors aged between 7 and 17, which further depicts the vulnerability of this category of persons. Incidents of gang-rape involved 2-6 perpetrators and also 
affected minors and elderly persons. Sexual assault which accounted for $1.6 \%$ of the cases was manifested through beating of men's private parts while women reported being groped on their breasts and private parts.

Cases of sexual and gender-based violence were widespread within the country and covered areas such as Bungoma in western Kenya, the capital City of Nairobi plus Migori and Kisumu in Nyanza region.

A total of Four reports namely: Fallacious Vote, Mirage at Dusk, Still a Mirage and Silhouettes of Brutality were produced by KNCHR. They give a human rights account of the 2017 election period in Kenya and record the numerous violations that occurred in the period when Kenyans set out at various stages to exercise their civil and political right to vote. It may therefore be stated categorically and without contradiction that sexual and gender-based violence (SGBV) formed an integral part of the violations experienced.

Included in the abovementioned reports are highlights of the various challenges that KNCHR faced in documenting the cases and also in seeking redress for the survivors. Amongst the recorded challenges are low levels of reporting by the citizenry due to fear of victimization by alleged perpetrators some of whom were community members well known to survivors, and fear of reprisals from security agents some who may still be serving in the locations where they committed the crimes. Another factor that may have contributed to low reporting was scepticism that attaches to the procedure that requires such reports to be made at police stations to colleagues of some of the perpetrators. The possibility that officers may fail to take the reports seriously or make the necessary effort to bring their colleagues to book or even impartially support prosecution of the cases through production of evidence and witnesses are real. Kenya's law also requires that collaborative medical evidence be collected within the recommended 72 hours after commission of a crime. This requirement often acts as an impediment since most victims may not be able to access health facilities within that period due to the attendant insecurity that prevails in the course of violent protests and police shoot outs. KNCHR urges NHRIs to note such and other relevant facts in order to seek ways of ameliorating them in the course of conducting their mandate under similar situations. Indeed in most conservative societies, sexual violence is a taboo subject that victims would rather maintain silence about and find alternative ways of coping with rather than risk exposure and the attendant stigmatization that may occur as a result of seeking medical attention or reporting.

Despite the fact that up to date the SGBV survivors of the $2007 / 8$ election violence in Kenya have yet to achieve justice, there is a lot to learn from KNCHR's exercise of its mandate during times of civil strife and division in society. NHRIs must of necessity step out to undertake proper documentation of the happenings for posterity and for use in seeking accountability at future opportune times. Such impartial objective reports can also be utilized to harness support from well-wishers in addressing sexual violence and thus provide the survivors with a much needed lifeline in their journey towards recovery. 
The reports could also form bases for evidence based interventions and formulation of policy and legislative reforms where gaps exist.

\section{Conclusion}

It remains evident that the right to sexual and reproductive health though not placed in any specific international instrument has still found expression and protection within provisions of various instruments at international, regional and local levels. NHRIs operating in monist states, such as Kenya, can support the realization of this right at national level through various means as the above examples from KNCHR's experiences illustrate. It is pertinent that NHRIs with a different legal framework will likewise find the above examples valuable. As far as it's practicable and within their mandate, it's imperative that NHRIs enhance efforts to advocate for ratification and thereafter domestication of relevant international and regional instruments. Such efforts will contribute to strengthening the protection and promotion of sexual and reproductive health rights at domestic level. This will be especially so when such efforts are complemented with strategies that align national law to each country's international obligations. Such multi-dimensional approaches will definitely prove worthwhile in providing a framework that gives stronger safeguards to the actualization of sexual and reproductive health rights to each NHRIs individual constituency.

\section{Notes}

1 CHOICE for Youth Organization 'Sexual and reproductive health and rights' https:// choiceforyouth.org/srhr/sexual-and-reproductive-health-and-rights/ (accessed 16 September 2020).

2 WHO Sexual health, human rights and the law: Working definition on sexual health (2015) 5.

3 As above.

4 As above.

5 As above.

$6 \mathrm{KNCHR}$ Realising sexual and reproductive health rights in Kenya: A myth or reality? A report of the public inquiry into violations of sexual and reproductive health rights in Kenya (2012) ii.

7 International Conference on Population and Development (ICPD) in Cairo, Egypt, on 5-13 September 1994 para 7.3.

8 F Banda 'Blazing the trail The African Women's Protocol comes into force' (2006) 50(1) Journal of African Law see also E Durojaye 'Addressing human rights concern raised by mandatory HIV Testing of pregnant women under the Protocol to the African Charter on the Rights of Women' (2008) 52 Journal of African Law 43-65.

9 C Ngwena 'Inscribing abortion as a human right: Significance of the Protocol on the Rights of Women in Africa' (2010) 32(4) Human Rights Quarterly 783-864.

10 E Durojaye \& O Oluduro 'The African commission on human and peoples' rights and the woman question' (2016) 24(3) Feminist Legal Studies 315-336; see also S Tamale 'The right to culture and the culture of rights: A critical perspective of women's sexual rights in Africa' (2008) 16 Feminist Legal Studies 147-169.

11 BBC News (2017) https://www.bbc.com/news/world-africa-39271850 of 17th March 2017 (accessed 29 August 2020). 
12 The Star Newspaper 'Doctors issue strike notice' (2018) https://www.the-star.co.ke/news/ 2018/01/19/doctors-issue-strike-notice- (accessed 19 January 2020).

13 S Asamba 'Nurses, Governors sign CBA ending 151-day strike' (2017) https://www. standardmedia.co.ke/health/article/2001259141/nurses-strike-finally-ends (accessed 19 January 2020).

14 See KNCHR The right to health, A case study of Kisumu Country (2017).

15 E Durojaye 'Turning paper promises to reality: National human rights institutions and adolescents' sexual and reproductive health' (2008) 26(4) Netherlands Quarterly of Human Rights 547-578.

16 As above.

17 Kenya Demographic and health survey 2008-09 (2010) https://dhsprogram.com/pubs/ $\mathrm{pdf} / \mathrm{fr} 229 / \mathrm{fr} 229 . \mathrm{pdf}$ (accessed 30 November 2019).

18 FIDA - Kenya and CRR - USA are NGOs registered and working in Kenya on issues that include reproductive health rights.

19 WHO World report on violence and health (2002) 5.

20 Kenya National Commission on Human Rights; Realising Sexual and Reproductive Health Rights in Kenya: A Myth or a Reality? A Report of the Public Inquiry into Violations of Sexual and Reproductive Health Rights in Kenya (2012) 76-77.

21 As above 79.

22 J Kiragu Status of gender based violence in Kenya (2011).

23 As above 81.

24 Kenya police medical examination form.

25 KNCHR Inquiry Report Realising sexual and reproductive health and rights in Kenya: $A$ myth or reality (2012).

26 WHO Safe abortion:Technical and policy guidance for health systems (2003) (2nd ed).

27 Established in June 2013.

28 An International Non-Governmental Organization that works on reproductive health rights.

29 Waki Commission information https://en.wikipedia.org/wiki/Waki_Commission (accessed 29 Aug 2020).

30 Kenya National Commission on Human Rights information www.knchr.org (accessed 15 August 2020.

31 KNCHR Silhouettes of brutality: An account of sexual violence during and after the 2017 elections (2018).

\section{References}

Asamba, S 'Nurses, governors sign CBA ending 151-day strike' (2017) https://www .standardmedia.co.ke/health/article/2001259141/nurses-strike-finally-ends (accessed 19 January 2020)

Banda, F 'Blazing the trail: The African women's protocol comes into force' (2006) 50(1) Journal of African Law 72

CHOICE for Youth Organization: Sexual and Reproductive Health and Rights https://choiceforyouth.org/srhr/sexual-and-reproductive-health-and-rights/ (accessed 16 September 2020)

Durojaye, E 'Addressing human rights concern raised by mandatory HIV testing of pregnant women under the protocol to the African Charter on the Rights of Women' (2008) 52 Journal of African Law 43-65

Durojaye, E 'Turning paper promises to reality: National human rights institutions and adolescents' sexual and reproductive health' (2008) 26(4) Netherlands Quarterly of Human Rights $547-578$ 


\section{Shatikha S. Chivusia}

Durojaye, E \& Oluduro, O 'The African commission on human and peoples' rights and the woman question’ (2016) 24(3) Feminist Legal Studies 315-336

Kenya Demographic and Health Survey 2008-09 (2010) https://dhsprogram.com/pubs/pdf /fr229/fr229.pdf (accessed 30 November 2019)

KNCHR www.knchr.org (accessed 15 August 2018)

KNCHR Inquiry Report 'Realising sexual and reproductive health rights in Kenya: A myth or reality' (2012)

KNCHR 'Realising sexual and reproductive health rights in Kenya: A myth or reality? A report of the public inquiry into violations of sexual and reproductive health rights in Kenya' (2012)

KNCHR 'Silhouettes of brutality: An account of sexual violence during and after the 2017 elections' (2018) www.knchr.org (accessed 15 August 2018)

KNCHR 'The right to health, a case study of Kisumu Country' (2017)

Ngwena, C 'Inscribing abortion as a human right: Significance of the protocol on the rights of women in Africa' (2010) 32 Human Rights Quarterly 4 783-864

Tamale, S 'The right to culture and the culture of rights: A critical perspective of women's sexual rights in Africa' (2008) 16 Feminist Legal Studies 147-169

World Health Organization Safe abortion: Technical and policy guidance for health systems (2 ed) (2003)

World Health Organization Sexual health, human rights and the law (2015)

World Health Organization World report on violence and health (2002) 